\title{
Size control and magnetic property trends in cobalt ferrite nanoparticles synthesized using an aqueous chemical route
}

Praveena Kuruva, Shidaling Matteppanavar, Srinath. S, and Tiju Thomas, Member, IEEE

\begin{abstract}
Cobalt ferrite $\left(\mathrm{CoFe}_{2} \mathrm{O}_{4}\right)$ is an engineering material which is used for applications such as magnetic cores, magnetic switches, hyperthermia based tumor treatment, and as contrast agents for magnetic resonance imaging. Utility of ferrites nanoparticles hinges on its size, dispersibility in solutions, and synthetic control over its coercivity. In this work, we establish correlations between room temperature co-precipitation conditions, and these crucial materials parameters. Furthermore post-synthesis annealing conditions are correlated with morphology, changes in crystal structure and magnetic properties. We disclose the synthesis and process conditions helpful in obtaining easily sinterable $\mathrm{CoFe}_{2} \mathrm{O}_{4}$ nanoparticles with coercive magnetic flux density $\left(\mathrm{H}_{c}\right)$ in the range 5.5-31.9 $\mathrm{kA} / \mathrm{m}$ and $M_{\mathrm{s}}$ in the range 47.9-84.9 $\mathrm{A} \cdot \mathrm{m}^{2} \mathrm{Kg}^{-1}$. At a grain size of $\sim 54 \pm 2 \mathrm{~nm}$ (corresponding to $1073 \mathrm{~K}$ sintering temperature), multi-domain behavior sets in, which is indicated by a decrease in $\mathbf{H}_{c}$. In addition, we observe an increase in lattice constant with respect to grain size, which is the inverse of what is expected of in ferrites. Our results suggest that oxygen deficiency plays a crucial role in explaining this inverse trend. We expect the method disclosed here to be a viable and scalable alternative to thermal decomposition based $\mathrm{CoFe}_{2} \mathrm{O}_{4}$ synthesis. The magnetic trends reported will aid in the optimization of functional $\mathrm{CoFe}_{2} \mathrm{O}_{4}$ nanoparticles.
\end{abstract}

Index terms - Ferrites, Ferrimagnetic materials, Cobalt compounds, Magnetic materials.

Praveena Kuruva is with the Materials Research Centre, Indian Institute of Science, Bangalore (e-mail: praveenauofhyd@gmail.com).

Shidaling Matteppanavar is with the Department of Physics, Bangalore University,Karnataka, India (e-mail: shipurn@gmail.com).

S. Srinath is with the School of Physics, University of Hyderabad, Andhra Pradesh, India (e-mail: sssp@uohyd.ernet.in).

Tiju Thomas works at the Materials Research Centre, Indian Institute of Science, Bangalore, Karnataka, India (email: tt332@ cornell.edu) 


\section{Introduction}

Ferrite systems continue to be of abiding interest due to their relevance to engineering and technology. This material system finds application in the magnetic core of coils in microwave frequency devices, and in computer memory core elements. Due to relatively low permeability and flux density, ferrites are useful in low field, low power applications. Ferrites also find use in low frequency applications such as timers, magnetic switches in refrigerators, air conditioners etc. Magnetic head transducers in recorders also employ ferrites [1]. In all these technologies, utility of ferrites is aided by particle size control, and synthetic control over coercivity.

More recently, nano-ferrites such as cobalt ferrite $\left(\mathrm{CoFe}_{2} \mathrm{O}_{4}\right)$ nanoparticles have found use in biomedical applications [2]. Currently these nanoparticles are being employed for a variety of applications such as hyperthermia based tumor treatment, and contrast agents for magnetic resonance imaging (MRI) or computer tomography [2, 3]. Apart from $\mathrm{CoFe}_{2} \mathrm{O}_{4}, \mathrm{Fe}_{3} \mathrm{O}_{4}[3,4]$ and polymer coated hybrid nanoparticles [5] have also been explored for use as contrast agents. In fact, there is significant effort being put into developing one-pot, synthetic approaches to such hybrids [6]. Low coercivity, easy surface functionalization, and biocompatibility are the primary factors that decide whether or not these nanomaterials are useful as contrast agents.

$\mathrm{CoFe}_{2} \mathrm{O}_{4}$ has also garnered the attention of researchers who hope to further improve or miniaturize magnetic memory devices. There are several on-going efforts in this direction to enhance device functionality of this nanomaterial by improving its coercivity and saturation magnetization [7, 8]. Considering all the applications of ferrites, it is clear that the practical use of its nanoparticles hinges on our ability to engineer its (i) particle size, (ii) dispersibility, (iii) coercivity, and (iv) remnant magnetization [9]. 
Besides its obvious technological importance, ferrites continue to be of tremendous scientific interest. For example, inter-particle interactions [10], behavior of ferrite nanomaterials in host lattice [11], impact of doping [12], ferrite based bi-magnetics [13] and magneto-optical properties [14] of this material are currently being pursued by several groups. Hence it is evident that "green routes" that allow particle size control of dispersible $\mathrm{CoFe}_{2} \mathrm{O}_{4}$ nanoparticles, while maintaining desirable magnetic properties (such as optimum coercivity and saturation magnetization) is important from the point of view of contemporary science and electrical engineering.

Currently thermal decomposition is considered better than co-precipitation for making uniformly sized ferrites [4], since thermal decomposition usually gives better size control. In applications such as contrast agents, size control is crucial to biocompatibility, since cytotoxicity is a function of both chemical composition and particle size [15]. These technical considerations raise a fundamental question: would it be possible to determine soft chemical co-precipitation conditions using which (i) size, and (ii) magnetic property optimization is possible? This is a relevant question since co-precipitation tends to be a much "greener" and easily scalable method for ferrite synthesis (when compared to thermal decomposition).

Green routes such as aqueous, low cost co-precipitation method usually result in materials with low crystallinity and poor monodispersity. However we demonstrate that with careful choice of co-precipitation conditions one can significantly minimize polydispersity. The scalable co-precipitation $\mathrm{CoFe}_{2} \mathrm{O}_{4}$ synthesis technique studied here is simple, quick, energy efficient, solvent free, and cost-effective. The method reported is an adaptation of the Yang et. al's method[16] which is helpful in synthesizing high specific surface area $\mathrm{CoFe}_{2} \mathrm{O}_{4}$. The reported method is a green, and viable alternative to other synthesis techniques currently used which (among others) 
include sol-gel [17], forced hydrolysis [18], combustion [19], micro-emulsion [20], mechano-chemical [21], and redox methods [22].

In this work we show that $\mathrm{pH}$ of the co-precipitation reaction mixture can be used to ensure significant reduction in polydispersity, and easy dispersibility of $\mathrm{CoFe}_{2} \mathrm{O}_{4}$ nanoparticles. Furthermore post-synthesis annealing can enable optimization of the magnetic properties of these materials. The aqueous synthesis method presented here results in particles that have high sinterability making it attractive for devices such as magnetostrictive sensors and actuators [23]. We quantify the role that thermal treatment plays in enhancing the magnetization and coercivity of these nanoparticles. Furthermore, we observe an increase in lattice constant with respect to grain size, which is the inverse of what is expected of in ferrites. Our results suggest that oxygen deficiency plays a crucial role in explaining this inverse trend. Synthesis-property correlations elaborated here will be useful in optimizing $\mathrm{CoFe}_{2} \mathrm{O}_{4}$ nanoparticles for a wide variety of engineering and bio-medical applications.

\section{Experimental}

$1 \mathrm{mM}$ of Cobalt nitrate $\left(\mathrm{Co}\left(\mathrm{NO}_{3}\right)_{2} \cdot 6 \mathrm{H}_{2} \mathrm{O}\right)$ and $2 \mathrm{mM}$ of ferric nitrate $\left(\mathrm{Fe}\left(\mathrm{NO}_{3}\right)_{2} \cdot 9 \mathrm{H}_{2} \mathrm{O}\right)$ are dissolved in $50 \mathrm{ml}$ of deionized (DI) water. $\mathrm{pH}$ of this solution is varied between 8.5 to 13 by careful, dropwise addition of $2 \mathrm{M} \mathrm{NaOH}$. This $\mathrm{pH}$ range is chosen based on known regions of formation of $\mathrm{Co}(\mathrm{OH})_{2}$, and iron(III) oxy-hydroxides [24, 25]. The mixture is stirred constantly, as the base is being added. The addition of base is accompanied by darkening of the reaction mixture. The temperature of the solution is maintained at about $333 \mathrm{~K}$. The process is continued for 2 hours, after which the particles formed are allowed to precipitate out. The supernatant water is poured out, and fresh DI water is used to wash the particles. This process of washing is repeated eight times to wash away the water soluble by-products. Thermogravimetric analysis 
(TGA), and Fourier transform infrared (FTIR) spectroscopy is performed on asprepared samples. Bruker Tensor 27 is used to perform FTIR, while Sieko TGA/DTA6200 Standard is used to perform TGA.

Pellets are prepared by sintering as-prepared powders at $673,773,873,973,1073$, and $1173 \mathrm{~K}$ for 2 hours. To characterize both as-prepared and sintered samples, a Phillips PANalytical X'pert powder X-ray diffractometer (XRD) is used, with $\mathrm{Cu} \mathrm{K}_{\alpha}(1.54 \AA$ ) radiation. The morphology of these powders are examined using a Carl Zeiss field emission scanning electron microscope (FE-SEM). Room temperature magnetic measurements are made using a vibrating sample magnetometer (VSM Lakeshore 7500, USA). The VSM chosen has a high field stability of $\pm 0.05 \% /$ day, and hence provides coercive field strength $\left(\mathrm{H}_{\mathrm{c}}\right)$ with very high precision and reproducibility. Transmission electron microscope (TEM) is performed using JEM-2010 from JEOL Inc. (Tokyo, Japan).

\section{Results and Discussions}

$\mathrm{X}$-ray diffraction (XRD) patterns of as-synthesized powders at different $\mathrm{pH}$ confirms the formation of $\mathrm{CoFe}_{2} \mathrm{O}_{4}$ (Figure 1.a). $\mathrm{CoFe}_{2} \mathrm{O}_{4}$ is found in inverse spinel structure, which has the general formula $\mathrm{AB}_{2} \mathrm{O}_{4}$ (where A: divalent metal ion, $\mathrm{B}$ : trivalent metal ion). In the normal spinel $\left(\mathrm{MgAl}_{2} \mathrm{O}_{4}\right)$ the oxygen atoms form a cubic close packed $(\mathrm{ABCABC})$ array, and the $\mathrm{Mg}^{2+}$ and $\mathrm{Al}^{3+}$ sits in tetrahedral (one-eighth occupied) and octahedral (half-occupied) sites in the lattice. An inverse spinel is an arrangement where the divalent ions (' $\mathrm{A}$ ' in the formula $\mathrm{AB}_{2} \mathrm{O}_{4}$ ) swap with half of the trivalent (' $\mathrm{B}$ ' in the formula $\mathrm{AB}_{2} \mathrm{O}_{4}$ ) ions so that the A-atoms now occupy octahedral sites.

Given the $\mathrm{pH}$ range chosen for $\mathrm{CoFe}_{2} \mathrm{O}_{4}$ synthesis, the precipitate phases expected are $\mathrm{Co}(\mathrm{OH})_{2}$, and hydroxylated anionic complexes such as $\mathrm{Fe}(\mathrm{OH})^{-1}{ }_{3}$, $\mathrm{Fe}(\mathrm{OH})^{2-}{ }_{4}$, and $\mathrm{Fe}(\mathrm{OH})^{-1}{ }_{4}[24,25]$. However, XRD clearly reveals $\mathrm{CoFe}_{2} \mathrm{O}_{4}$ 
formation showing that the $\mathrm{Co}(\mathrm{OH})_{2}$ and hydroxylated iron complexes co-precipitate out of the reaction mixture to form single phase $\mathrm{CoFe}_{2} \mathrm{O}_{4}$. XRD shows no peaks corresponding to $\mathrm{Co}(\mathrm{OH})_{2}$ or any of the oxides or hydroxides of $\mathrm{Fe}$, confirming that the only crystalline phase obtained is $\mathrm{CoFe}_{2} \mathrm{O}_{4}$. All peaks could be indexed using JCPDS card number 22-1086. The (3 11 1) reflection which is characteristic of ferrite particles $[21,26]$ is seen in every sample synthesized.

The Scherrer formula is used to determine the crystallite size of as-synthesized powders. The crystallite size of the as-synthesized $\mathrm{CoFe}_{2} \mathrm{O}_{4}$ samples are estimated from X-ray peak broadening of the $\left(\begin{array}{lll}3 & 1 & 1\end{array}\right)$ peak using. In order to ensure that the crystallite size determined is correct, lattice strain is evaluated using Rietveld refinement. Even when lattice strain is taken into account the crystallite size obtained is in good agreement with the value obtained using the Scherrer formula. Peak broadening and TEM images confirm that the particles formed are indeed in the nanoregime (Figure 1.b). With increase in $\mathrm{pH}$, the $\left(\begin{array}{lll}3 & 1 & 1\end{array}\right)$ peak broadening decreases, indicating an increase in crystallite size. Increase in crystallite size with $\mathrm{pH}$ is likely due to the faster particle growth kinetics favored by high $\mathrm{pH}$. It is also observed that with increasing $\mathrm{pH}$, there is an increase in the lattice constant and average crystallite size (Figure 1.c).

Lattice constants of materials synthesized are always close to the values of the $\mathrm{CoFe}_{2} \mathrm{O}_{4}$ synthesized by other methods $[27,28]$. The concomitant increase in lattice constant with the particle size is akin to the report by D. Thapa et. al [28]. She showed that this trend is the inverse of what usually occurs (in ferrites usually a decrease in particle size is accompanied by increase in lattice constant) [29]. She shows that in ferrite systems $\left(\mathrm{CuFe}_{2} \mathrm{O}_{4}\right.$ in her case), the usual trend can be reversed due to the 
conversion of a small fraction of $\mathrm{Fe}^{3+}$ to $\mathrm{Fe}^{2+}$ [28]. This is most likely the cause for our observation as well, wherein we see an increase in lattice constant with particle size increase. This is reasonable since in the synthesis conditions (temperature: $333 \mathrm{~K}$, $\mathrm{pH}>8.5)$, Fe prefers to be divalent [25].

The mechanism of formation of $\mathrm{CoFe}_{2} \mathrm{O}_{4}$ most likely involves the coprecipitation of mixed amorphous hydroxides of $\mathrm{Co}$ and $\mathrm{Fe}$. An indication of this mechanism comes from the TGA performed on as-prepared samples (Figure 1.d). As synthesized powders show multi-step weight loss, indicating that the as-prepared material is a complex mixture with several amorphous phases, in addition to crystalline $\mathrm{CoFe}_{2} \mathrm{O}_{4}$. Weight loss at and below $373 \mathrm{~K}$ (region I) is due to loss of water molecules. The weight loss seen just above $400 \mathrm{~K}$ (region II) is attributed to decomposition of Fe-rich mixed nitrates, since decomposition temperature of pure $\mathrm{Fe}\left(\mathrm{NO}_{3}\right)_{3}$ is about $430 \mathrm{~K}$ [30]. Weight loss occurring beyond $520 \mathrm{~K}$ (region III) is attributed to Co-rich mixed hydroxides [31]. Beyond $620 \mathrm{~K}$ (region IV), the weight loss observed is likely due to the decomposition of both Fe-rich mixed hydroxides, and $\mathrm{Co}\left(\mathrm{NO}_{3}\right)_{3}[31,32]$. No evidence of crystalline $\mathrm{Co}(\mathrm{OH})_{3}$ and $\mathrm{Fe}(\mathrm{OH})_{3}$ exists, hence it is very likely that mixed amorphous hydroxides (indicated by TGA measurements) act as precursors for the co-precipitation of $\mathrm{CoFe}_{2} \mathrm{O}_{4}$ nanoparticles.

Presence and role of mixed hydroxides is also indicated by FTIR measurements performed on as-prepared samples (Figure 1.e). The assigned peak positions are tabulated in Table 1. For example, an IR band around $1600 \mathrm{~cm}^{-1}$ observed in as-prepared samples could be due to $\mathrm{OH}^{-1}$ or molecular $\mathrm{H}_{2} \mathrm{O}$. Presence of residual nitrates is confirmed by the $1379 \mathrm{~cm}^{-1} \mathrm{IR}$ peak, which is associated with the asymmetric stretching of $\mathrm{NO}_{3}^{-1}$. The FTIR spectra obtained is quite broad for all the samples. Such broadening is commonly observed for inverse spinel ferrites $\left(\mathrm{MFe}_{2} \mathrm{O}_{4}\right)$. 
Two main broad peaks are seen around $400-300 \mathrm{~cm}^{-1}$ and $600-500 \mathrm{~cm}^{-1} .600-500 \mathrm{~cm}^{-1}$ stretches corresponds to intrinsic stretching vibrations of the metal-oxygen bonds, where the metal is at the tetrahedral site. $400-300 \mathrm{~cm}^{-1}$ (more accurately $430-385 \mathrm{~cm}^{-}$ $\left.{ }^{1}\right)$ band is because of metal-oxygen stretching where metal is in the octahedral site. The band at $975 \mathrm{~cm}^{-1}$ is due to the stretching vibration of $\mathrm{Fe}-\mathrm{Co}$ bonds [33]. The broadening in this peak could be due to the statistical distribution of Fe at A and B sites in the inverse spinel structure. From the figure, it seems likely that this statistical distribution of $\mathrm{Fe}$ in $\mathrm{A}$ and $\mathrm{B}$ sites becomes more pronounced, when nanoparticles are synthesized at high $\mathrm{pH}(\mathrm{say} \geq 8)$. This could very well be associated with the faster coprecipitation kinetics, which takes place at higher $\mathrm{pH}$. It may be noted that it is this faster growth kinetics which is also responsible for larger crystallites at higher $\mathrm{pH}$.

Polydispersity in the annealed samples is measured using an index of dispersion called Fano factor. In this case, it is the ratio of the variance $\left(\sigma^{2}\right)$ to the mean size (d). Samples with relatively low Fano factor are less polydisperse when compared to those with larger Fano factors. Both the variance and the mean size is obtained using image analysis (performed using ImageJ software) on SEM images. The particle size distribution is obtained by analyzing 6 SEM images for each sample. We notice that the particle size distribution follows a log-normal distribution regardless of synthesis $\mathrm{pH}$.

Particles synthesized at $\mathrm{pH} 13$ show the best dispersability (Table 2). These particles (i.e those synthesized at $\mathrm{pH} 13$ ) are annealed at 673, 773, 873, 973, 1073, and $1173 \mathrm{~K}$. XRD on annealed samples reveal improvement in crystallinity as a result of heat treatment (Figure $2 \mathrm{a}, \mathrm{b}$ ). Rietveld refinement of $\mathrm{CoFe}_{2} \mathrm{O}_{4}$ annealed at $1073 \mathrm{~K}$ is shown in Figure 2 c. Widths of IR bands (Figure $2 \mathrm{~d}$ ) in the range $500-1000 \mathrm{~cm}^{-1}$ are found to reduce with sintering temperature. In fact the $975 \mathrm{~cm}^{-1}$ peak, the width of 
which is a measure of statistical distribution of $\mathrm{Fe}$ in $\mathrm{A}$ and $\mathrm{B}$ sites [33], also reduces with sintering. This is an indication of better crystallinity and order in sintered samples. IR bands corresponding to residual nitrates $\left(1379 \mathrm{~cm}^{-1}\right)$ and water $\left(1600 \mathrm{~cm}^{-}\right.$ ${ }^{1}$ ) are not seen in sintered samples.

SEM images (Figure 3 a) show that the $\mathrm{CoFe}_{2} \mathrm{O}_{4}$ annealed nanocrystals possess spherical shape. The average particle size observed is close to the values obtained using the Scherrer equation. Hence it is very likely that each of the observed particles is a single crystallite. The physical size of the $\mathrm{CoFe}_{2} \mathrm{O}_{4}$ crystals increases with the annealing temperature since, at high temperatures the solid-vapour interfaces tend to be replaced by solid-solid interface via solid-state diffusion. This phenomenon has been observed in several systems (including ferrites), and is attributed to the crystal's tendency to reduce the overall surface energy [34].

Increase in annealing temperature results in particle size distributions with lower Fano factors, which implies that annealing promotes monodispersity (Table 3). Also, increase in annealing temperatures result in larger particle and crystallite sizes, and is accompanied by marginal increase in the lattice parameter (Figure $3 \mathrm{~b}$, Table 4). However in all the sintered samples, the particle size distribution is found to be log-normal (Figure $3 \mathrm{c}$ ).

In samples sintered at higher temperatures, increase in grain size is accompanied by an increase in lattice constant. This trend is the opposite of what is usually expected in ferrites, wherein lattice constant increases with decreasing particle size [29]. Earlier in this paper, we mentioned that the "inverse trend" is also observed when $\mathrm{CoFe}_{2} \mathrm{O}_{4}$ is precipitated out at different $p H$ values. Hence in $\mathrm{CoFe}_{2} \mathrm{O}_{4}$ synthesized by the method presented here, an inverse particle size-lattice constant relationship is observed. Recently D. Thapa et al. showed that the "inverse trend" (i.e increase in lattice 
constant with increase in particle size) occurs in ferrites when a fraction of $\mathrm{Fe}^{3+}$ converts to $\mathrm{Fe}^{2+}$. Hence process conditions that aid in the conversion of $\mathrm{Fe}^{3+}$ to $\mathrm{Fe}^{2+}$ would cause an increase in magnetization. She also observes that calcination aids in the conversion of $\mathrm{Fe}^{3+}$ to $\mathrm{Fe}^{2+}$ (in case of $\mathrm{CuFe}_{2} \mathrm{O}_{4}$ ) [28]. Using energy dispersive $\mathrm{x}$ ray analysis, we find that sintering results in change in $\mathrm{O}: \mathrm{Fe}$ ratio. In fact the O:Fe ratio changes from 2.00 when sintering temperature is $673 \mathrm{~K}$, to 1.99 when sintering temperature is $>1073 \mathrm{~K}$. We also find that increasing synthesis $\mathrm{pH}$ results in oxygen deficiency. Hence we infer that the $\mathrm{Fe}^{3+} \rightarrow \mathrm{Fe}^{2+}$ reduction process is aided by (i) high $\mathrm{pH}$ in the co-precipitation chamber, and (ii) increase in annealing temperature. Due to the higher magnetic moment associated with $\mathrm{Fe}^{2+}$, the observed increase in magnetization with increasing calcination temperatures is expected. Given that $\mathrm{Fe}^{2+}$ rich (i.e oxygen deficient) ferrites are expected to have the "inverse" lattice constantsize relationship [28], the inverse trend we observe in our samples is reasonable.

The main aim of synthesizing the $\mathrm{CoFe}_{2} \mathrm{O}_{4}$ nanocrystallites by chemical coprecipitation is to obtain a magnetic material with good magnetization $\left(\mathrm{M}_{\mathrm{s}}\right)$. In addition knowledge of correlation between coercive field $\left(\mathrm{H}_{\mathrm{c}}\right)$, synthesis and process conditions is useful from the point of view of manufacturing technology. The maximum magnetic field applied is $1.5 \mathrm{~T}$. All magnetic measurements (see Table 5) are carried out at room temperature. Hysteresis loops of samples annealed at different temperatures are provided (Figure $4 \mathrm{a}, \mathrm{b}) . \mathrm{M}_{\mathrm{s}}$ and remnant magnetization $\left(\mathrm{M}_{\mathrm{r}}\right)$ monotonically increases with respect to temperature (Figure 4 (c, d)). This is consistent with the fact that higher annealing temperatures aids in the conversion of a certain fraction of $\mathrm{Fe}^{3+}$ to $\mathrm{Fe}^{2+}$ in ferrites. This atomistic process tends to not only increase the unit cell volume, but also results in increased magnetization [28]. 
The coercive field $\mathrm{H}_{\mathrm{c}}$ reaches a maximum of $31.9 \mathrm{kA} / \mathrm{m}$ for sample calcined at 1073 $\mathrm{K}$ (Figure $4 \mathrm{e}$ ); which corresponds to an average crystallite size of $\sim 54 \mathrm{~nm}$. This maximum coercive field is lesser than the highest value reported for $\mathrm{CoFe}_{2} \mathrm{O}_{4}$. In general, micron-sized particles tend to have much higher coercivity $(\sim 114.9 \mathrm{kA} / \mathrm{m})$ [35]. This suggests that the method presented here results in softer ferrite particles. Results presented here also show how synthesis and calcination conditions can be used to control $\mathrm{H}_{\mathrm{c}}$ and $\mathrm{M}_{\mathrm{s}}$ of $\mathrm{CoFe}_{2} \mathrm{O}_{4}$ nanoparticles.

In $\mathrm{CoFe}_{2} \mathrm{O}_{4}$ nanoparticles that fall within the size regime reported here $(\sim 50 \mathrm{~nm})$, fairly high room temperature coercivities have been reported (as much as $96.6 \mathrm{kA} / \mathrm{m}$ ) $[36,37]$. Even in super-paramagnetic $\mathrm{CoFe}_{2} \mathrm{O}_{4}$ particles, which are otherwise very small (typically $<10 \mathrm{~nm}$ ), coalescence and aging results in agglomerates that are $\sim 50$ nm, which show comparable room temperature coercivities (i.e 96 kA/m) [36]. In comparison, particles reported here have $\mathrm{H}_{\mathrm{c}}$ in the range 5.5-31.9 kA/m. Even the sample with the highest $\mathrm{M}_{\mathrm{s}}\left(84.9 \mathrm{~A} \cdot \mathrm{m}^{2} \cdot \mathrm{Kg}^{-1}\right)$, has a $\mathrm{H}_{\mathrm{c}}$ of only about $5.5 \mathrm{kA} / \mathrm{m}$ (Fig 4 (c, e)). This makes materials reported here desirable from the point of view of practical applications. It must be noted that the best $\mathrm{M}_{\mathrm{s}}$ reported here is an improvement over previous reports on $\mathrm{CoFe}_{2} \mathrm{O}_{4}$ nanoparticles (in the $\leq 50 \mathrm{~nm}$ size regime). The $\mathrm{M}_{\mathrm{s}}$ of $\mathrm{CoFe}_{2} \mathrm{O}_{4}$ nanoparticles are usually $\sim 69 \mathrm{~A} \cdot \mathrm{m}^{2} \cdot \mathrm{Kg}^{-1}$ [36-38], while we obtain $~ 84.9 \mathrm{~A} \cdot \mathrm{m}^{2} \cdot \mathrm{Kg}^{-1}$. The $\mathrm{Fe}^{3+}$ to $\mathrm{Fe}^{2+}$ conversion in these samples, which is discussed above, is most likely responsible for the observed enhancement of $\mathrm{M}_{\mathrm{s}}$ in our samples.

Beyond a certain calcination temperature $(\sim 1073 \mathrm{~K})$, the crystallite size continues to increase with sintering temperature; however the $\mathrm{H}_{\mathrm{c}}$ decreases (Figure 4 e). This is most likely due to a change in behavior from single domain to multidomain [26]. The squareness factor $\left(\mathrm{M}_{\mathrm{r}} / \mathrm{M}_{\mathrm{s}}\right)$ also monotonically increases with 
calcination temperatures, suggesting an increase in magnetocrystalline anisotropy (Table 5). We believe this increase in magnetocrystalline anisotropy is most likely due to improvement in crystal order and structure, expected in samples calcined at high temperatures.

\section{Conclusions}

Synthesis and process conditions are explored to obtain fairly monodisperse, easily sinterable $\mathrm{CoFe}_{2} \mathrm{O}_{4}$ nanoparticles with $\mathrm{M}_{\mathrm{s}}$ in the range $\left(47.9-87.9 \mathrm{~A} \cdot \mathrm{m}^{2} \cdot \mathrm{Kg}^{-1}\right.$ ) and $\mathrm{H}_{\mathrm{c}}$ in the range $5.5-31.9 \mathrm{kA} / \mathrm{m}$. The technique presented here is a viable alternative to thermal decomposition for obtaining functional ferrite nanoparticles, since size control is indeed possible using this approach. The method presented in green and easily scalable.

Dispersity is found to be best for particles synthesized at $\mathrm{pH} \sim 13$. Both increase in $\mathrm{pH}$ (during co-precipitation) and calcination temperature result in simultaneous increase in lattice constant and average particle size. This trend is the inverse of the usual trend for ferrites, wherein lattice constant increases with decreasing particle size. The observed "inverse trend" is likely due to the fact that both high $\mathrm{pH}$ of synthesis and high calcination temperatures promote $\mathrm{Fe}^{3+} \rightarrow \mathrm{Fe}^{2+}$ conversion. Increase in $\mathrm{pH}$ and calcination temperature is helpful in minimizing the polydispersity in co-precipitation synthesized $\mathrm{CoFe}_{2} \mathrm{O}_{4}$.

Increasing calcination temperature results in particles with better $\mathrm{M}_{\mathrm{s}}$ and improved squareness factor. Beyond a domain size of $\sim 54 \mathrm{~nm}$, a single domain to multi-domain transition results in lowering of $\mathrm{H}_{\mathrm{c}}$. The simplicity, cost-effectiveness, high yield ( $96 \%)$ and scalability of the method ensures its viability for commercial applications (eg. magnetic storage, ferrofluids, contrast agents in MRI etc). The easy adaptability 
of the technique makes it promising for obtaining related doped and undoped ferrite systems.

\section{Acknowledgments}

K. Praveena thanks University Grants Commission (UGC), New Delhi for providing the D. S. Kothari Postdoctoral Fellowship. She also thanks Prof. S. Srinath (University of Hyderabad) for helpful discussions. Tiju Thomas acknowledges the financial support received from the "Department of Science and Technology, Government of India”, in the form of grant no. DST01117.

\section{References}

[1] N. A. Spaldin Magnetic Materials : Fundamentals and Applications U.K.: Cambridge University Press, 2011.

[2] R. C. Pullar "Hexagonal ferrites: A review of the synthesis, properties and applications of hexaferrite ceramics," Progress in Materials Science vol. 57, pp. 1191-1334, 2012.

[3] J. Trekker, K. Jans , H. Damm , D. Mertens , T. Nuytten , J. Vanacken, et al., "Synthesis of PEGylated Magnetic Nanoparticles With Different Core Sizes," IEEE Transactions on Magnetics, vol. 49, pp. 219-227, 2013.

[4] N. Lee and T. Hyeo "Designed synthesis of uniformly sized iron oxide nanoparticles for efficient magnetic resonance imaging contrast agents," Chemical Society Review, vol. 41, pp. 2575-2589, 2012.

[5] D. Kim, M. K. Yu , T. S. Lee, J. J. Park, Y. Y. Jeong, and S. Jon "Amphiphilic polymer-coated hybrid nanoparticles as CT/MRI dual contrast agents," Nanotechnology, vol. 22, p. 155101, 2011.

[6] M. Zhong, P. Fei , X. Fu , Z. Lei , and B. Su "Synthesis of PS-CoFe2O4 Composite Nanomaterial with Improved Magnetic Properties by a One-Step Solvothermal Method," Industrial and Engineering Chemistry Research, vol. 52 (24), pp. 8230-8235, 2013.

[7] M. Staruch, D. Hires, D. Violette, D. Navarathne, G. A. Sotzing, and M. Jaina "Structural and Magnetic Properties of $\mathrm{CoFe}_{2} \mathrm{O}_{4}$ and $\mathrm{Co}_{0.5} \mathrm{Zn}_{0.5} \mathrm{Fe}_{2} \mathrm{O}_{4}$ Nanoparticles for the Magnetoelectric Composite Films," Integrated Ferroelectrics: An International Journal vol. 131, pp. 102-109, 2011.

[8] M. Ning, J. Li, C. K. Ong, and S. J. Wang, "High perpendicular coercive field of (100)-oriented CoFe2O4 thin films on Si (100) with $\mathrm{MgO}$ buffer layer," Journal of Applied Physics vol. 103, p. 013911, 2008.

[9] Q. Dai, M. Lam, S. Swanson, R.-H. R. Yu, D. J. Milliron, T. Topuria, et al., "Monodisperse Cobalt Ferrite Nanomagnets with Uniform Silica Coatings," Langmuir vol. 26, p. 17546, 2010.

[10] D. Peddis, F. Orrù, A. Ardu, C. Cannas, A. Musinu, and G. Piccaluga, "Interparticle Interactions and Magnetic Anisotropy in Cobalt Ferrite Nanoparticles: Influence of Molecular Coating," Chemistry of Materials vol. 24, pp. 1062-1071, 2012. 
[11] M. Vasilakaki, D. Peddis, and D. Fiorani, "Memory Effects in Ultra-Small CoFe O Nanoparticles," IEEE Transactions on magnetics vol. 48, p. 1305, 2012.

[12] L. Hu, C. de Montferrand, Y. Lalatonne, L. Motte, and A. Brioude, "Effect of Cobalt Doping Concentration on the Crystalline Structure and Magnetic Properties of Monodisperse CoxFe3-xO4 Nanoparticles within Nonpolar and Aqueous Solvents," The Journal of Physical Chemistry C vol. 116, pp. 43494355, 2012.

[13] Q. Song and Z. J. Zhang "Controlled Synthesis and Magnetic Properties of Bimagnetic Spinel Ferrite $\mathrm{CoFe} 2 \mathrm{O} 4$ and $\mathrm{MnFe} 2 \mathrm{O} 4$ Nanocrystals with CoreShell Architecture," Journal of American Chemical Society vol. 134, pp. 10182-10190, 2012.

[14] E. Fantechi, G. Campo, D. Carta, A. Corrias, C. de Julián Fernández, D. Gatteschi, et al., "Exploring the Effect of Co Doping in Fine Maghemite Nanoparticles," The Journal of Physical Chemistry C vol. 116, pp. 8261-8270, 2012.

[15] C. Porredon, J. de Lapuente, G. Jesús Pablo, S. Judith, C. Argelia , E. Ainhoa, et al., "Toxicology Review in Metal Nanoparticles: Approximation in Gold and Cobalt Ferrite Nanoparticles," Advanced Science Letters vol. 6, pp. 1-16, 2012.

[16] X. Yang, X. Wang, and Z. Zhang "Electrochemical properties of submicron cobalt ferrite spinel through a co-precipitation method," Journal of Crystal Growth, vol. 277, pp. 467-470, 2005.

[17] S. R. Naik and A. V. Salker, "Change in the magnetostructural properties of rare earth doped cobalt ferrites relative to the magnetic anisotropy," Journal of Materials Chemistry, vol. 22, pp. 2740-2750 2012.

[18] M. Artus, L. B. Tahar, F. Herbst, L. Smiri, F. Villain, N. Yaacoub, et al., "Size-dependent magnetic properties of $\mathrm{CoFe}_{2} \mathrm{O}_{4}$ nanoparticles prepared in polyol," Journal of Physics: Condensed Matter vol. 23, p. 506001, 2011.

[19] M. Khandekar, R. Kambale, J. Patil, Y. Kolekar, and S. Suryavanshi, "Effect of calcination temperature on the structural and electrical properties of cobalt ferrite synthesized by combustion method," Journal of Alloys and Compounds, vol. 509, pp. 1861-1865, 2011.

[20] N. R. Panchal and R. B. Jotania, "Cobalt ferrite nano particles by microemulsion route " Nanotechnology and Nanoscience, vol. 1, pp. 17-18, 2010.

[21] E. Manova, B. Kunev, D. Paneva, I. Mitov, and L. Petrov, "MechanoSynthesis, Characterization, and Magnetic Properties of Nanoparticles of Cobalt Ferrite, $\mathrm{CoFe}_{2} \mathrm{O}_{4}$," Chemistry of Materials vol. 16, pp. 5689-5696, 2004.

[22] Z. Gu, X. Xiang, G. Fan, and F. Li, "Facile Synthesis and Characterization of Cobalt Ferrite Nanocrystals via a Simple Reduction-Oxidation Route," The Journal of Physical Chemistry C, vol. 112, pp. 18459-18466, 2008.

[23] D. C. Jiles, J. A. Paulsen, J. E. Snyder, C. C. H. Lo, A. P. Ring, and K. A. Bormann, "Cobalt ferrite based magnetostrictive materials for magnetic stress sensor and actuator applications," U.S. Patent, 2008.

[24] J. Chivot, L. Mendoza, C. Mansour, T. Pauporté, and M. Cassir, "New insight in the behaviour of $\mathrm{Co}-\mathrm{H}_{2} \mathrm{O}$ system at $25-150{ }^{\circ} \mathrm{C}$, based on revised Pourbaix diagrams," Corrosion Science vol. 50, pp. 62-69, 2008. 
[25] B. Beverskog and I. Puigdomenech, "Revised pourbaix diagrams for iron at 25-300 ${ }^{\circ} \mathrm{C} "$ Corrosion Science, vol. 38, pp. 2121-2135, 1996.

[26] P. Yaseneva, M. Bowker, and G. Hutchings, "Structural and magnetic properties of Zn-substituted cobalt ferrites prepared by co-precipitation method," Physical Chemistry Chemical Physics, vol. 13, p. 18609, 2011.

[27] Y. Cedeño-Mattei and O. Perales-Pérez "Synthesis of high-coercivity cobalt ferrite nanocrystals," Microelecronics vol. 40, pp. 673-676, 2009.

[28] D. Thapa, N. Kulkarni, S. N. Mishra, P. L. Paulose, and P. Ayyub "Enhanced magnetization in cubic ferrimagnetic $\mathrm{CuFe}_{2} \mathrm{O}_{4}$ nanoparticles synthesized from a citrate precursor: the role of $\mathrm{Fe}^{2+}, "$ Journal of Physics D: Applied Physics, vol. 43, p. 195004, 2010.

[29] P. Ayyub, V. R. Palkar, S. Chattopadhyay, and M. Multani, "Effect of crystal size reduction on lattice symmetry and cooperative properties," Physical Review B vol. 51, pp. 6135-6138, 1995.

[30] K. K. Wieczorek-Ciurowa, A. J., "The Thermal Decomposition of $\mathrm{Fe}\left(\mathrm{NO}_{3}\right)_{3} \cdot 9 \mathrm{H}_{2} \mathrm{O}$," Journal of Thermal Analysis and Calorimetry, vol. 58, pp. 647-651, 1999.

[31] S. Yuvaraj, L. Fan-Yuan, C. Tsong-Huei, and Y. Chuin-Tih, "Thermal Decomposition of Metal Nitrates in Air and Hydrogen Environments," The Journal of Physical Chemistry B vol. 107, pp. 1044-1047, 2003.

[32] N. Koga, S. Takemoto, S. Okada, and H. Tanaka, "A kinetic study of the thermal decomposition of iron(III) hydroxide oxides. Part 1. $\alpha-\mathrm{FeO}(\mathrm{OH})$ in banded iron formations," Thermochimica Acta, vol. 254, pp. 193-207, 1995.

[33] L. Zhao, H. Zhang, Y. Xing, S. Song, S. Yu, W. Shi, et al., "Studies on the magnetism of cobalt ferrite nanocrystals synthesized by hydrothermal method," Journal of Solid State Chemistry, vol. 181, pp. 245-252, 2008.

[34] Z. Wang, X. Liu, M. Lv, P. Chai, Y. Liu, X. Zhou, et al., "Preparation of OneDimensional $\mathrm{CoFe}_{2} \mathrm{O}_{4}$ Nanostructures and Their Magnetic Properties," The Journal of Physical Chemistry C, vol. 112, p. 15171, 2008.

[35] V. Pillai and D. O. Shah "Synthesis of high-coercivity cobalt ferrite particles using water-in-oil microemulsions," Journal of Magnetism and Magnetic Materials vol. 163, pp. 243-248, 1996.

[36] N. Bao, L. Shen, A. W. Yu-Hsiang, J. Ma , D. Mazumdar, and G. Arunava "Controlled Growth of Monodisperse Self-Supported Superparamagnetic Nanostructures of Spherical and Rod-Like $\mathrm{CoFe}_{2} \mathrm{O}_{4}$ Nanocrystals," Journal of American Chemical Society, vol. 131 pp. 12900-12901, 2009.

[37] B. G. Toksha, S. E. Shirsath, S. M. Patange, and K. M. Jadhav "Structural investigations and magnetic properties of cobalt ferrite nanoparticles prepared by sol-gel auto combustion method," Solid State Communications, vol. 147 pp. 479-483, 2008.

[38] S. H. Xiao, W. F. Jiang, L. Y. Li , and X. Jian "Low-temperature autocombustion synthesis and magnetic properties of cobalt ferrite nanopowder," Materials Chemistry and Physics, vol. 106 pp. 82-87, 2007. 


\section{FIGURE CAPTIONS}

Figure 1: (a) XRD patterns of $\mathrm{CoFe}_{2} \mathrm{O}_{4}$ samples synthesized at two different $\mathrm{pH}$ values (8.5, and 13.0). (b) TEM of $\mathrm{CoFe}_{2} \mathrm{O}_{4}$ nanoparticles synthesized at $\mathrm{pH}$ 13. (c) Average crystallite size and lattice parameters (extracted from XRD) increase with respect to $\mathrm{pH}$. (d) Thermogravimetry is used to obtain normalized weight loss (as a function of temperature) of samples prepared. Region I represents loss of water, II is due to decomposition of Fe-rich mixed nitrates, region III is likely due to Co-rich mixed hydroxides, and region IV is attributed to the decomposition of Fe-rich mixed hydroxides, and $\mathrm{Co}\left(\mathrm{NO}_{3}\right)_{3}$. (e) Shows FTIR spectra of samples prepared at various $\mathrm{pH}$ values.

Figure 2: (a) $\mathrm{XRD}$ patterns of $\mathrm{CoFe}_{2} \mathrm{O}_{4}$ nanoparticles (prepared at $\mathrm{pH}$ 13), annealed at different temperatures (b) Shows change in the characteristic (311) peak when the sample is annealed at different temperatures. FIGURE 2: (c) Shows the Rietveld refined XRD pattern of $\mathrm{CoFe}_{2} \mathrm{O}_{4}$ annealed at $1173 \mathrm{~K}$. The fitting is very close to the experimental $\mathrm{XRD}$, since the error (blue line) in Rietveld fitting is found to be minimal. (d) FTIR of sintered $\mathrm{CoFe}_{2} \mathrm{O}_{4}$ at different temperatures.

Figure 3: (a) Shows scanning electron micrographs of samples annealed at 773, 873, 973, 1073, 1173 and $1273 \mathrm{~K}$ respectively. Increasing annealing temperature promotes agglomeration of particles, and leads to larger particle sizes. (b) Both the average crystallite size and lattice constant increases with respect to the annealing temperature. (c) Shows the log-normal particle size distribution in $\mathrm{CoFe}_{2} \mathrm{O}_{4}$ sample which was co-precipitated at pH 13 and annealed at $1173 \mathrm{~K}$. Distribution obtained using image analysis (using ImageJ software) is used to determine mean particle size and variance. All samples studied show log-normal particle size distribution. 
Figure 4: (a) $\mathrm{M}-\mathrm{H}$ hysteresis curves for particles prepared at $\mathrm{pH} \mathrm{13,} \mathrm{and} \mathrm{annealed} \mathrm{at}$ different temperatures. (b) Shows how $\mathrm{M}_{\mathrm{r}}$ and $\mathrm{H}_{\mathrm{c}}$ is extracted using $\mathrm{M}-\mathrm{H}$ curves. The M-H loop provided is that which is obtained using $\mathrm{CoFe}_{2} \mathrm{O}_{4}$ co-precipitated at $\mathrm{pH} 13$, and annealed at $1073 \mathrm{~K}$. (c, d) Show variation of saturation magnetization $\left(\mathrm{M}_{\mathrm{s}}\right)$ and remnant magnetization $\left(\mathrm{M}_{\mathrm{r}}\right)$ with respect to annealing temperature. Both these magnetic quantities increase monotonically with respect to calcination temperature. $(\mathrm{e}, \mathrm{f})$ Coercive field $\left(\mathrm{H}_{\mathrm{c}}\right)$ of $\mathrm{CoFe}_{2} \mathrm{O}_{4}$ increases with respect to annealing temperature. However the $H_{c}$ reaches a maximum value when the grain size reaches $54 \pm 2 \mathrm{~nm}$. The decrease in $\mathrm{H}_{\mathrm{c}}$ beyond this grain size is most likely due to a single domain to multidomain transition. 


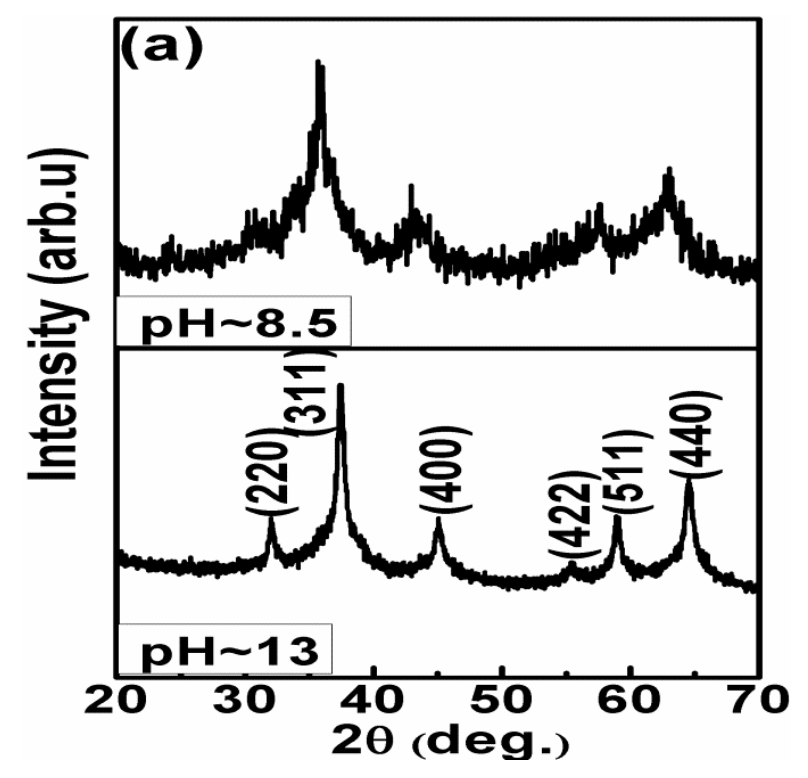

(b)
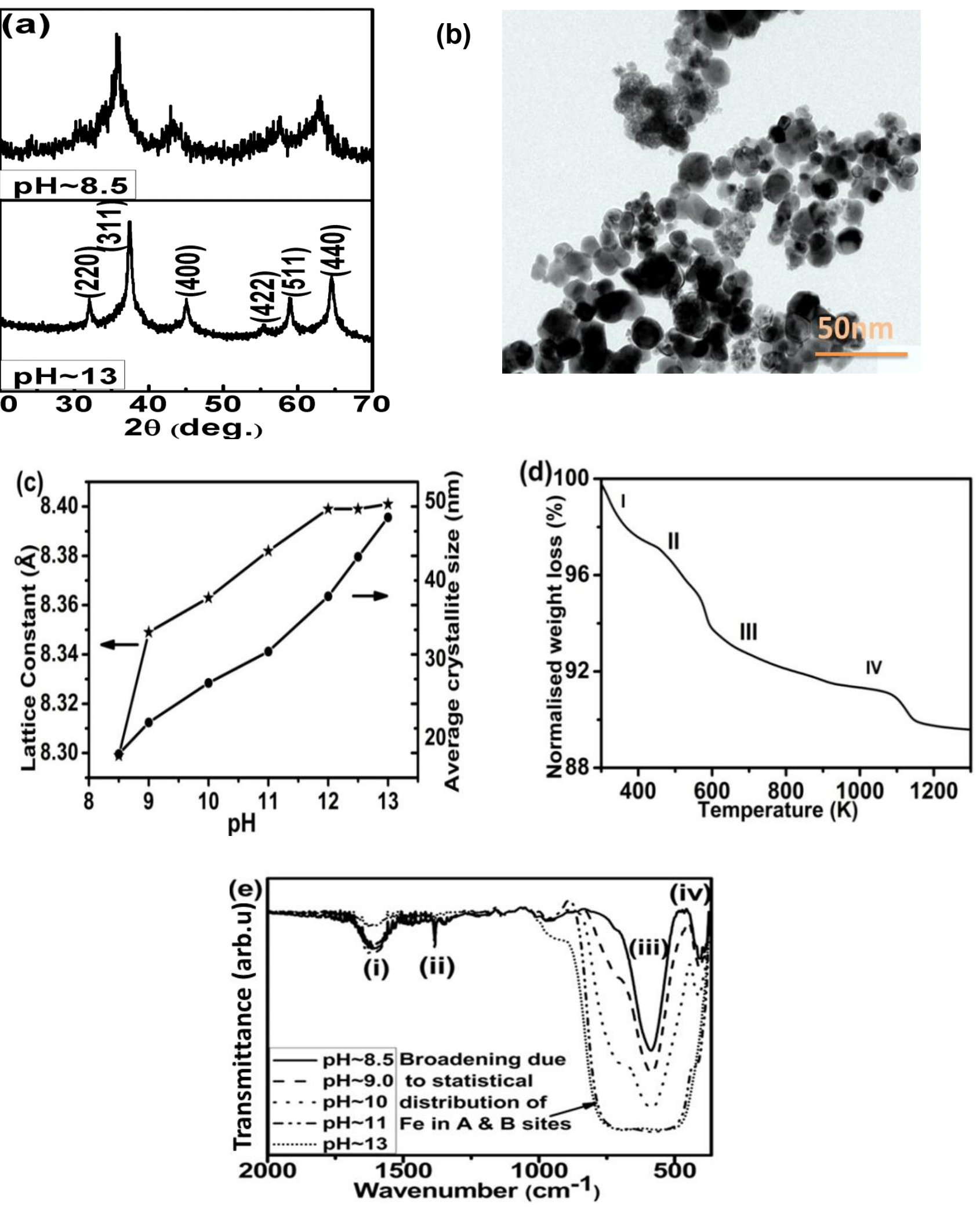
(a)

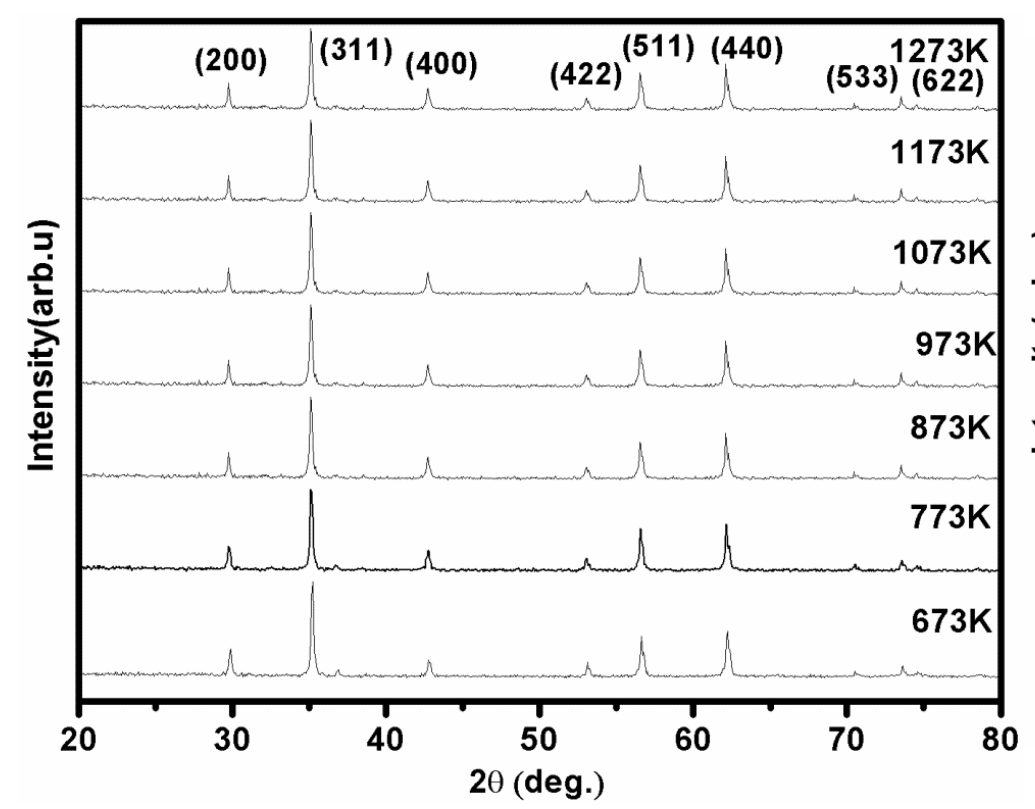

(b)

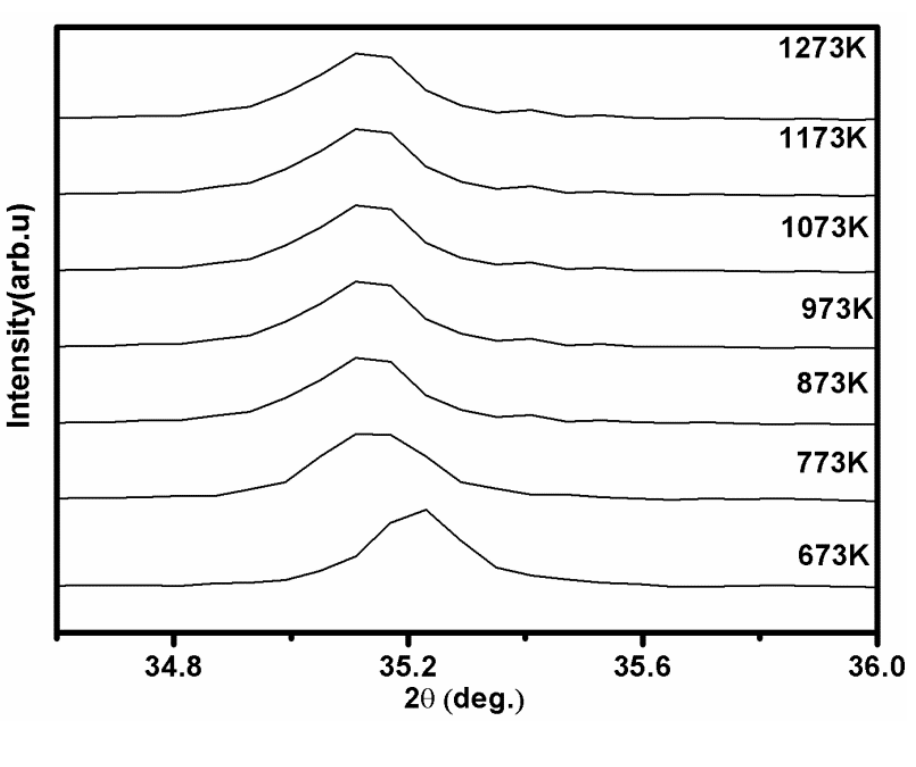

(c)

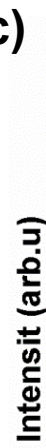

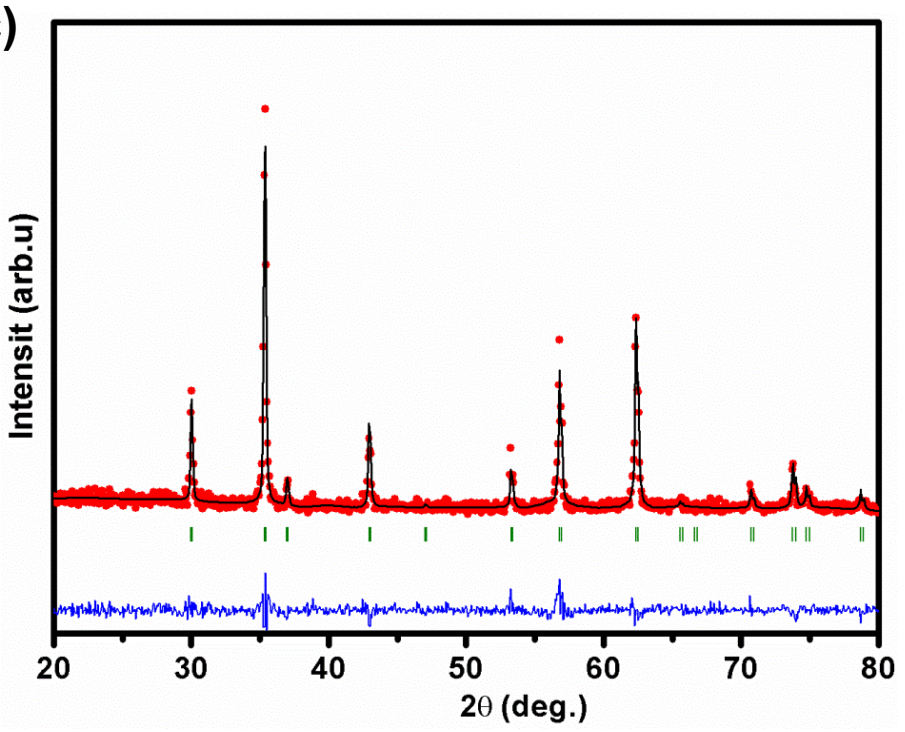

(d)

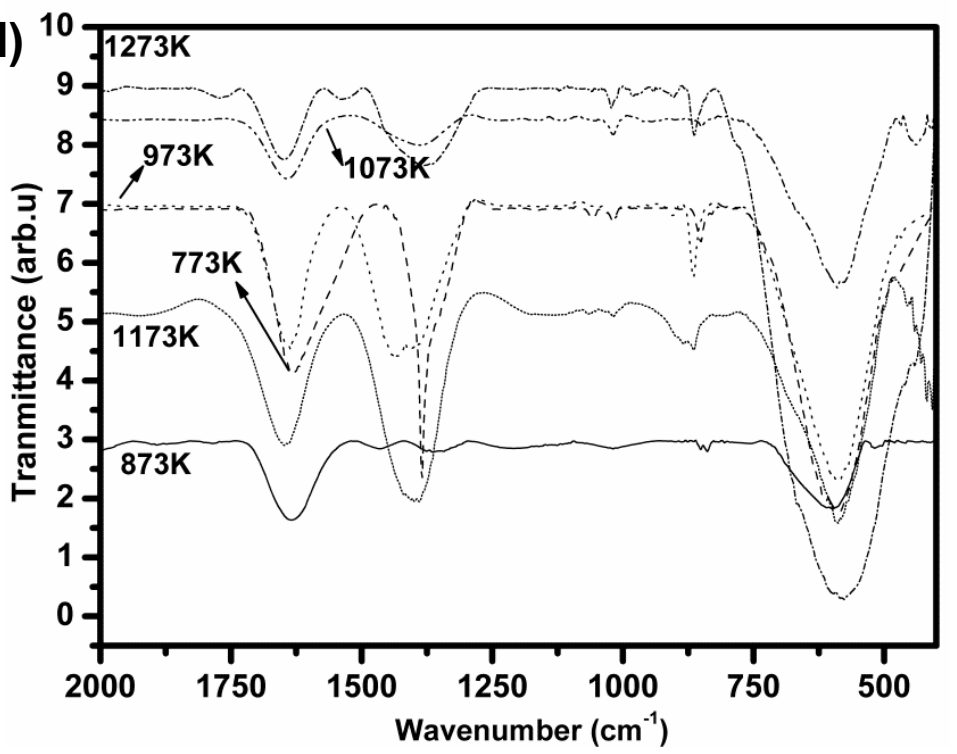


(b)

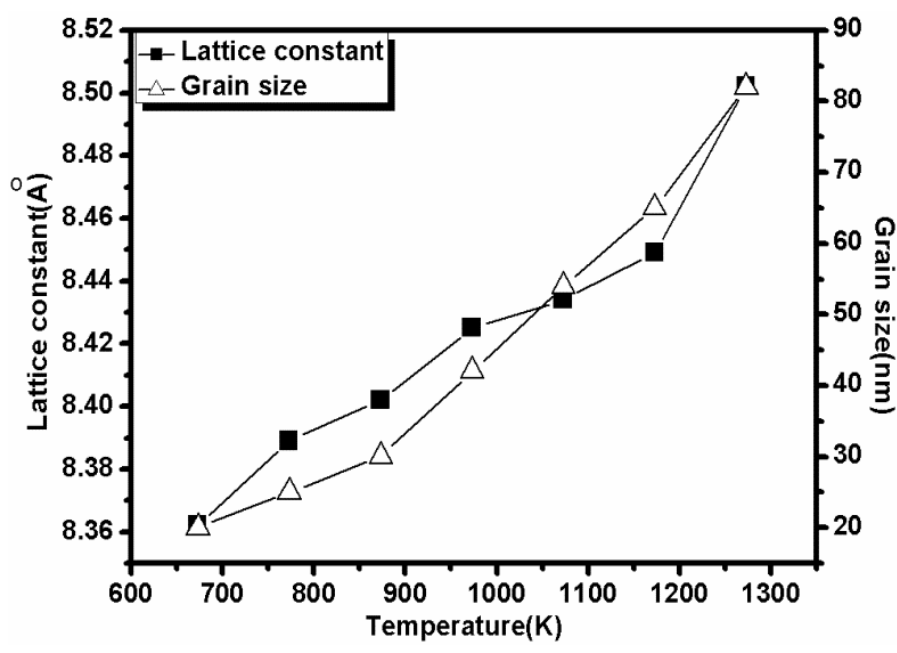

(a)
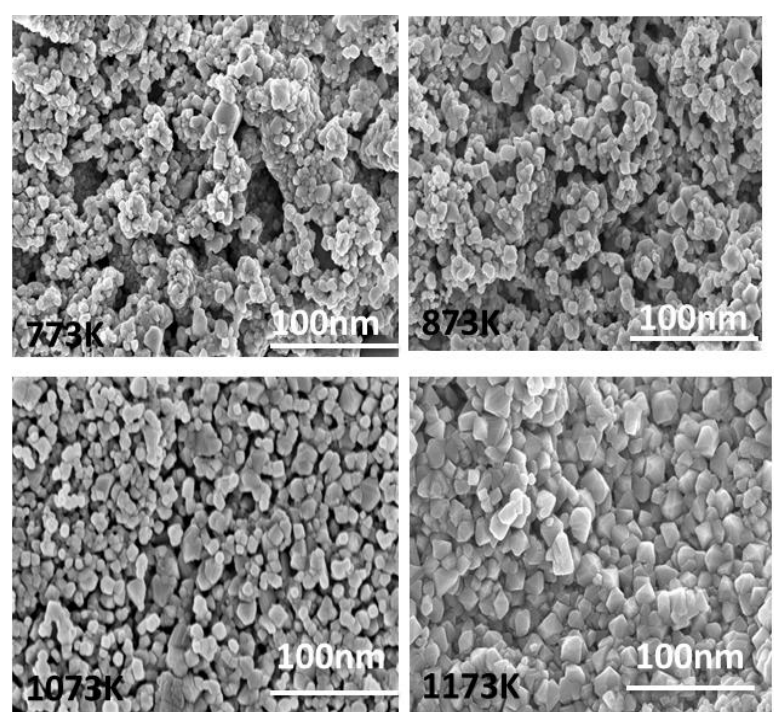

(c)

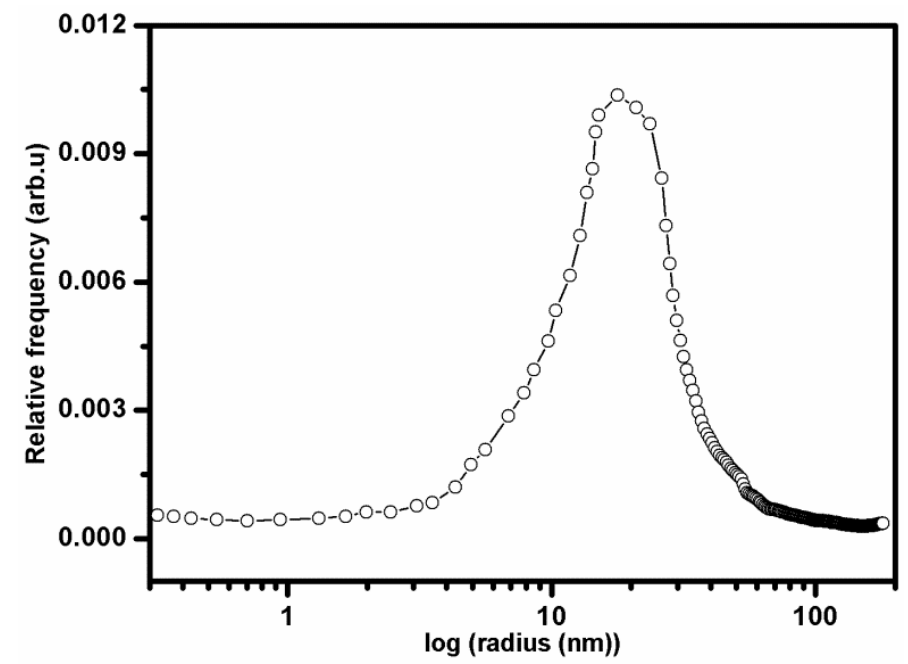


(a)

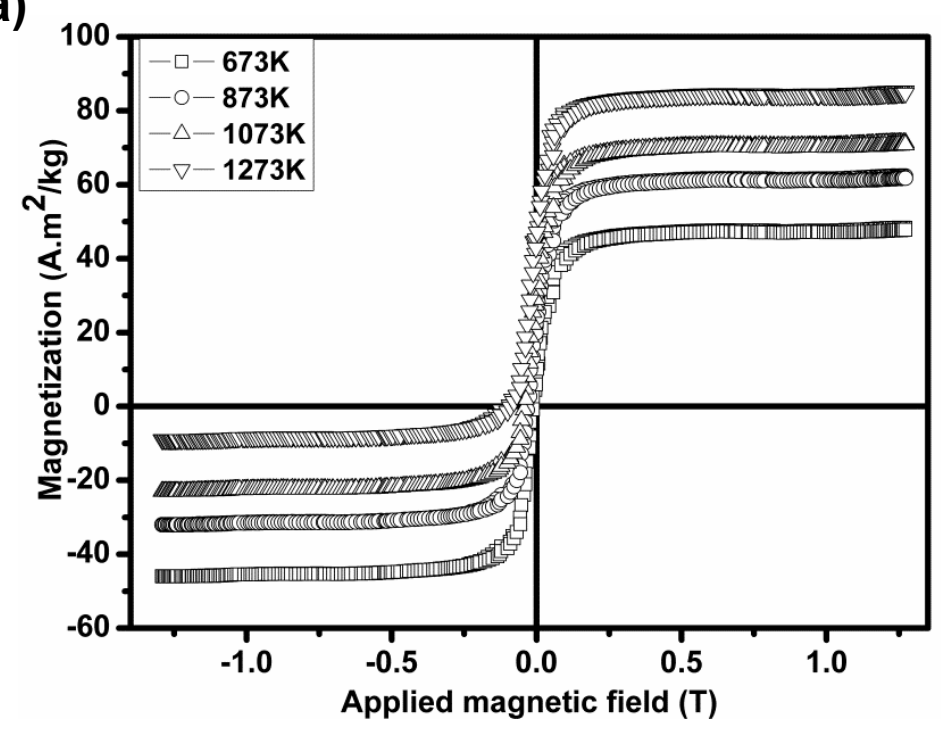

(c)

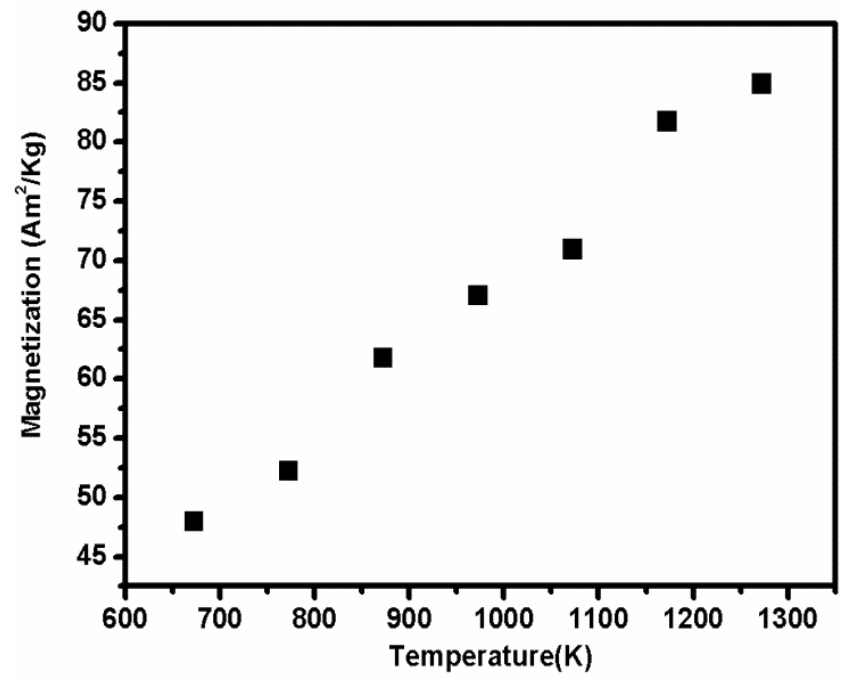

(b)

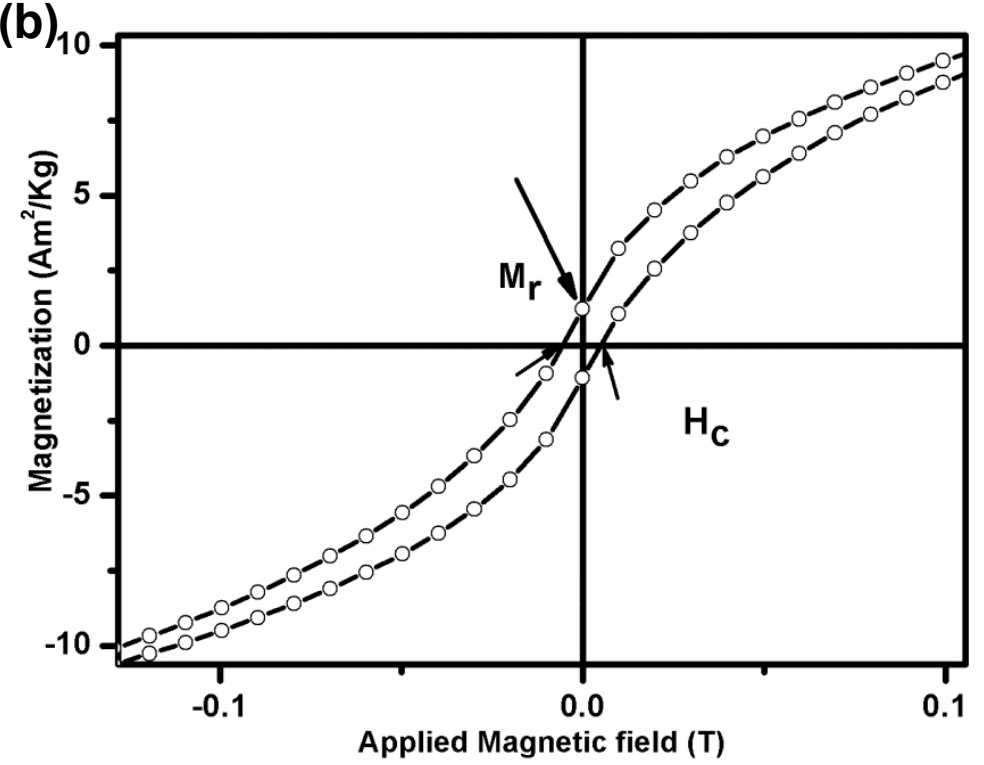

(d)

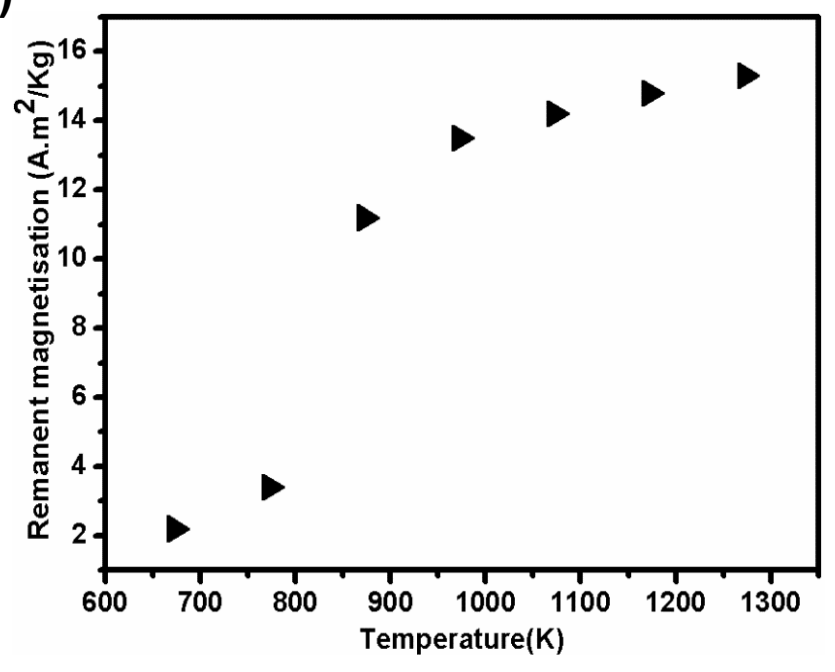


(e)

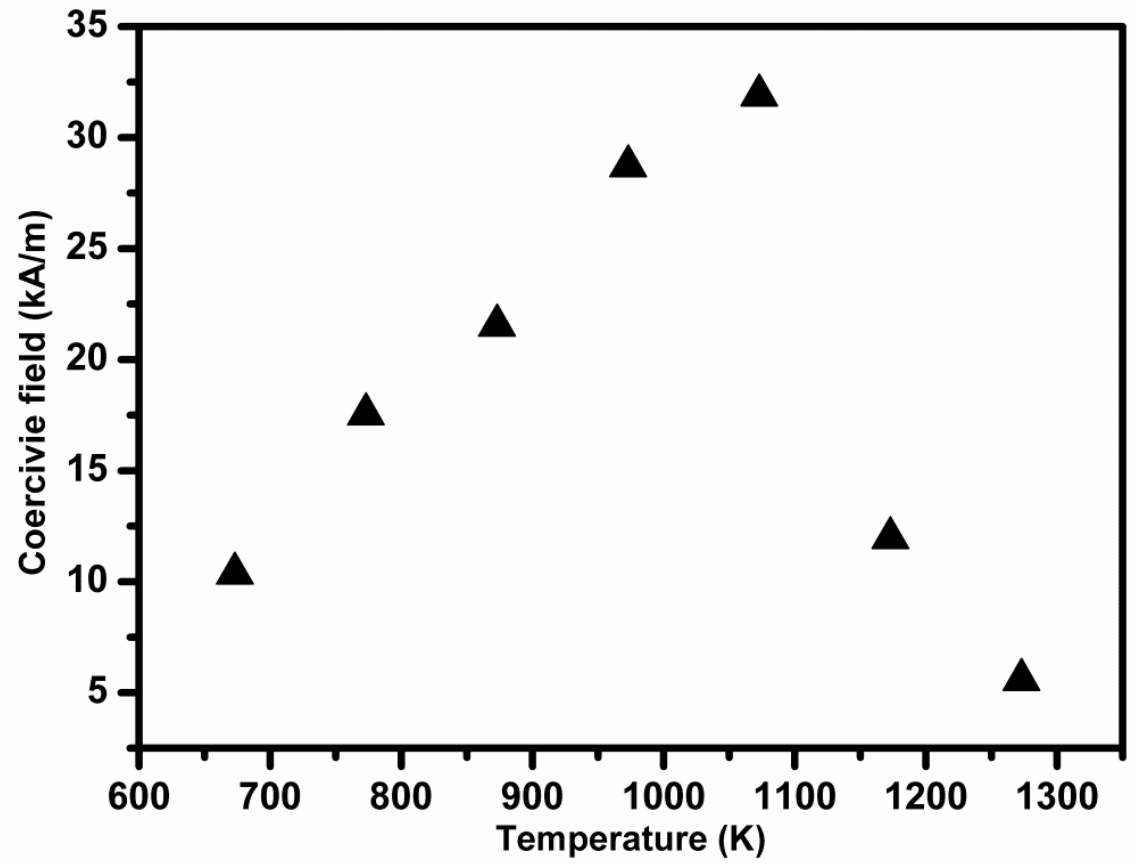

(f)

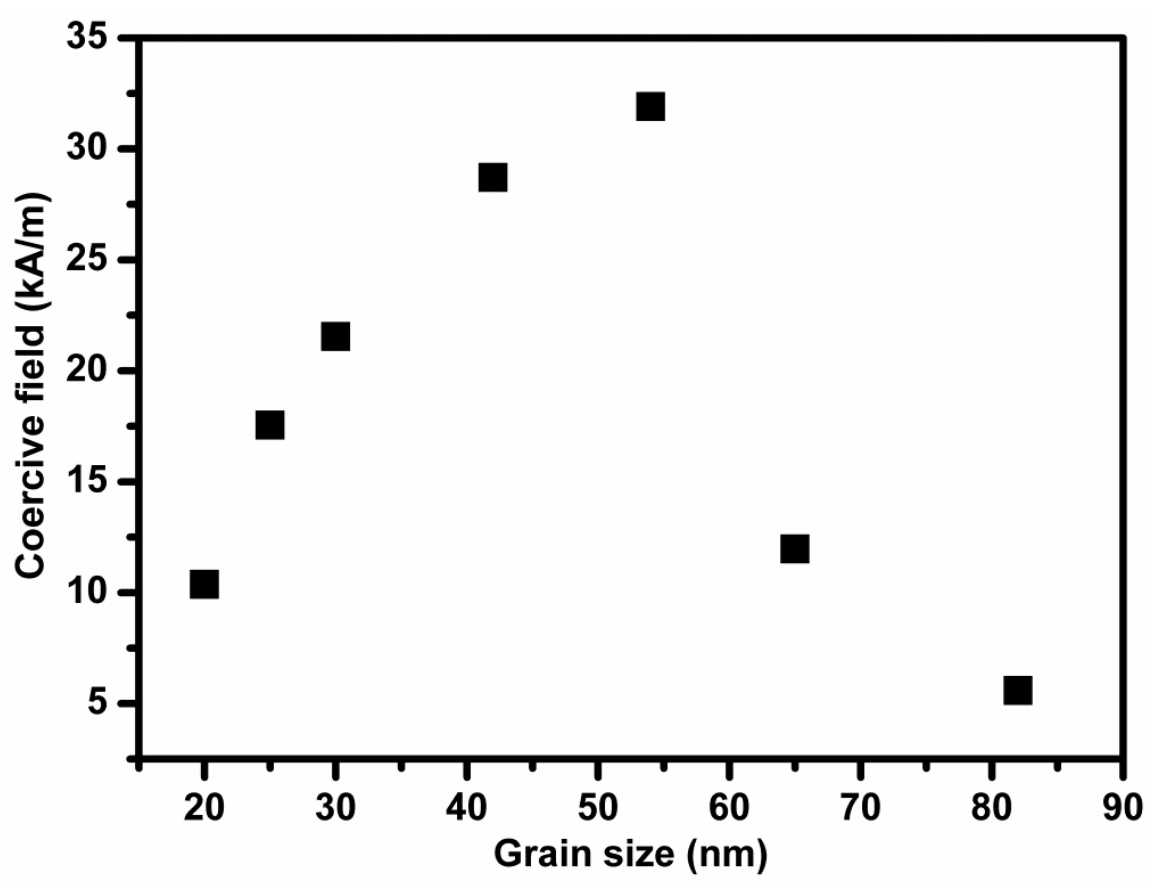


Table 1. List of peak positions form FTIR analysis of $\mathrm{CoFe}_{2} \mathrm{O}_{4}$.

\begin{tabular}{ll}
\hline $\begin{array}{l}\text { Peak } \\
\text { positions }\end{array}$ & Assignments \\
\hline 1600 & $\mathrm{OH}^{-1}$ or $\mathrm{H}_{2} \mathrm{O}$ molecule \\
\hline 1379 & $\mathrm{NO}_{3}{ }^{-1}$ \\
\hline 975 & $\mathrm{Fe}-\mathrm{Co}$ bonds \\
\hline $600-500$ & Intrinsic stretching vibrations of the metal oxygen bonds \\
\hline $400-385$ & Metal tetrahedral \\
\hline
\end{tabular}


Table 2. Average crystallite size (mean $(d)$ and variance $(\sigma)$ using SEM based image analysis. The Fano factor $\left(\sigma^{2} / \mathrm{d}\right)$ is used as the index of dispersion. Increasing $\mathrm{pH}$ of the synthesis bath results in monotonic reduction in polydispersity.

\begin{tabular}{llll}
\hline $\mathrm{pH}$ & $\sigma(\mathrm{nm})$ & $\mathrm{d}(\mathrm{nm})$ & $\sigma^{2} / \mathrm{d}$ \\
\hline 8.5 & 13.7 & 18 & 10.4 \\
\hline 9.4 & 13.8 & 22 & 8.6 \\
\hline 10 & 14.1 & 27 & 7.4 \\
\hline 11 & 14.5 & 31 & 6.7 \\
\hline 12 & 15.2 & 38 & 6.1 \\
\hline 12.5 & 15.5 & 43 & 5.5 \\
\hline 13 & 15.7 & 48 & 5.1 \\
\hline
\end{tabular}


Table 3. Variation of dispersity (measured in the form of Fano factor $\left(\sigma^{2} / \mathrm{d}\right)$ with respect to calcination temperature. Calcination reduces the polydispersity of $\mathrm{CoFe}_{2} \mathrm{O}_{4}$ particles, synthesized at $\mathrm{pH} 13$.

\begin{tabular}{llll}
\hline $\begin{array}{l}\text { Temperature } \\
(\mathrm{K})\end{array}$ & $\begin{array}{l}\mathrm{D} \\
(\mathrm{nm})\end{array}$ & $\sigma(\mathrm{nm})$ & $\left(\sigma^{2} / \mathrm{d}\right)$ \\
\hline 673 & 23 & 13.9 & 8.3 \\
\hline 773 & 27 & 13.9 & 7.1 \\
\hline 873 & 35 & 14 & 5.6 \\
\hline 973 & 46 & 14.5 & 4.5 \\
\hline 1073 & 53 & 15.3 & 4.3 \\
\hline 1173 & 69 & 15.5 & 3.4 \\
\hline 1273 & 88 & 15.8 & 2.8 \\
\hline
\end{tabular}


Table 4. Rietveld refinement of $\mathrm{CoFe}_{2} \mathrm{O}_{4}$ and comparison of lattice constants. $\mathrm{a}_{0}$ is the reported lattice constant, as in JCPDS 22-1086.

\begin{tabular}{llll}
\hline Temperature (K) & $\begin{array}{l}\text { Lattice } \\
\text { constant (a) }(\AA) \\
\text { XRD }\end{array}$ & $\begin{array}{l}\text { Lattice } \\
\text { Constant }(\AA) \text { XRD } \\
\text { refinement }\end{array}$ & $\begin{array}{l}\text { Strain } \\
a-a_{0} / a\end{array}$ \\
\hline 673 & 8.36 & 8.37 & 0.004 \\
\hline 773 & 8.39 & 8.38 & 0.000 \\
\hline 873 & 8.40 & 8.39 & 0.000 \\
\hline 973 & 8.43 & 8.41 & 0.005 \\
\hline 1073 & 8.43 & 8.42 & 0.005 \\
\hline 1173 & 8.45 & 8.44 & 0.007 \\
\hline 1273 & 8.50 & 8.49 & 0.013 \\
\hline
\end{tabular}


Table 5. Grains size, lattice constant, remnant magnetization $\left(\mathrm{M}_{\mathrm{r}}\right)$, saturation magnetization $\left(\mathrm{M}_{\mathrm{s}}\right)$ and $\mathrm{H}_{\mathrm{c}}$ (coercive field) of $\mathrm{CoFe}_{2} \mathrm{O}_{4}$ sintered at different temperatures. Beyond $1073 \mathrm{~K}$ (corresponding to grains of size $\sim 54 \mathrm{~nm}$ ), $\mathrm{H}_{\mathrm{c}}$ reduces, which is most likely due to a single to multi-domain transition.

\begin{tabular}{llllll}
\hline $\begin{array}{l}\text { Temperature } \\
(\mathrm{K})\end{array}$ & $\begin{array}{l}\text { Lattice } \\
\text { constant } \\
(\AA)\end{array}$ & $\begin{array}{l}\mathrm{M}_{\mathrm{s}} \\
\left(\mathrm{A} . \mathrm{m}^{2} / \mathrm{Kg}\right)\end{array}$ & $\begin{array}{l}\mathrm{M}_{\mathrm{r}} \\
\left(\mathrm{A} . \mathrm{m}^{2} / \mathrm{Kg}\right)\end{array}$ & $\mathrm{M}_{\mathrm{r}} / \mathrm{M}_{\mathrm{s}}$ & $\begin{array}{l}\mathrm{H}_{\mathrm{c}} \\
(\mathrm{kA} / \mathrm{m})\end{array}$ \\
\hline 673 & 8.36 & 47.9 & 2.2 & 0.05 & 10.4 \\
\hline 773 & 8.39 & 52.2 & 3.4 & 0.07 & 17.5 \\
\hline 873 & 8.40 & 61.8 & 11.2 & 0.18 & 21.5 \\
\hline 973 & 8.43 & 67.1 & 13.5 & 0.20 & 28.7 \\
\hline 1073 & 8.43 & 70.9 & 14.2 & 0.20 & 31.9 \\
\hline 1173 & 8.45 & 81.7 & 14.8 & 0.18 & 11.9 \\
\hline 1273 & 8.50 & 84.9 & 15.3 & 0.18 & 5.6 \\
\hline
\end{tabular}

